\section{The interaction between bronchoconstriction and cough in asthma}

\begin{abstract}
Variable airflow obstruction is a pathophysiological hallmark of asthma; however, the interactions between acute bronchoconstriction and the cough reflex are poorly understood. We performed a randomised, single-blind, placebo-controlled, crossover study to investigate the interaction between bronchoconstriction and cough in asthma. Capsaicin was administered to evoke coughs and methacholine to induce bronchoconstriction. We demonstrated that acute bronchoconstriction increased capsaicinevoked coughs, which improved as airway calibre spontaneously resolved. However, capsaicin-evoked coughing had no impact on methacholine-induced bronchoconstriction. This study provides evidence that bronchoconstriction increases the activation of capsaicin-responsive airway nerves, but the precise mechanisms and mediators involved require further evaluation.
\end{abstract}

\section{Trial registration number}

ISRCTN14900082.

\section{BACKGROUND}

The pathophysiological hallmarks of asthma are airway inflammation, bronchial hyperresponsiveness (BHR) and variable airflow obstruction, which manifest as symptoms of wheeze, cough, shortness of breath and chest tightness. However, the mechanisms linking the pathophysiology to symptoms are unclear. For example, the interactions between bronchospasm and cough are poorly understood. Our previous work in stable asthma has demonstrated that cough responses to citric acid and capsaicin are not correlated with methacholine BHR or $\mathrm{FEV}_{1} .{ }^{1}{ }^{2}$ The effects of acute bronchoconstriction on cough responses evoked by capsaicin inhalation have only been studied in healthy volunteers where minimal bronchoconstriction (mean $\mathrm{FEV}_{1}$ fall 8.8\%) had no effect on the capsaicin concentration provoking two coughs (C2). ${ }^{3}$ We aimed to investigate the interaction between acute bronchoconstriction and cough reflex activation in individuals with mild atopic asthma. See online supplement for additional details.

\section{METHODS}

Participants with controlled mild atopic asthma were recruited, but not selected for symptoms of cough. We performed an eight-visit, randomised, single-blind, placebo controlled crossover study (see online supplementary figure E1).

On visit 1, participants underwent history and examination, spirometry and capsaicin cough challenge; four inhalations of doubling concentrations of capsaicin $\quad(0.48-1000 \mu \mathrm{mol} / \mathrm{L}, \quad 30 \mathrm{~s}$ apart), coughs counted in the first $15 \mathrm{~s}$ after each inhalation. ${ }^{4}$ The challenge was completed when the volunteer reached the final or maximum tolerated dose. The maximum evoked coughs were denoted $\mathrm{E}_{\max }$ and the dose evoking half of this response as $\mathrm{ED}_{50}$. Individual $\mathrm{ED}_{50}$ doses of capsaicin were then used to evoke cough at subsequent visits. At visit $2, \geq 48$ hours later, participants underwent methacholine challenge ( 2 min tidal breathing) to evaluate $\mathrm{PC}_{20} ;{ }^{5}$ the concentration preceding this was used to initiate bronchoconstriction at future visits. Participants next entered a three-period, single-blinded, randomised, crossover study with $\geq 48$ hours between visits. At visits 3 and 4 (period 1), the effect of bronchoconstriction on capsaicin-evoked cough responses was assessed. Subjects were randomised to inhale either saline or methacholine for $2 \mathrm{~min}$ to achieve a fall in \% $\mathrm{FEV}_{1}$ of $15 \%-25 \%$ (concentration from visit 2, next doubling concentration inhaled if required), followed immediately by $\mathrm{ED}_{50}$ capsaicin (four inhalations, $30 \mathrm{~s}$ apart). At visits 5 and 6 (period 2), the effect of cough reflex activation on BHR was assessed. Participants were randomised to either $\mathrm{ED}_{50}$ capsaicin or saline, followed by the methacholine concentration selected at visit 2 . At visits 7 and 8 (period 3), we assessed the effect of spontaneous recovery of bronchoconstriction on evoked cough responses. Visits 7 and 8 were identical to visits 3 and 4 , except after inhaling methacholine or saline, participants received $\mathrm{ED}_{50}$ capsaicin immediately and again at 30 and $60 \mathrm{~min}$. Spirometry was performed before and after all challenges and participants were discharged when $\mathrm{FEV}_{1}$ returned to $\geq 90 \%$ of baseline. A cough monitor (Vitalograph, UK) was worn throughout visits to document the number of evoked coughs and also spontaneous coughing.

\section{RESULTS}

Fourteen participants were enrolled and completed periods 1 and 2 (mean $( \pm S D$ ) age 24.2 years $( \pm 3.8), 64 \%$ female, body mass index $23.5 \mathrm{~kg} / \mathrm{m}^{2}( \pm 3.1), \mathrm{FEV}_{1} \%$ predicted $96.4( \pm 11.1), \mathrm{PC}_{20} 2.0 \mathrm{mg} / \mathrm{mL}$ $( \pm 2.3)$ see online supplementary table E1). Fifty per cent were taking salbutamol as required, while the remainder were also taking low dose ICS $(150 \mu \mathrm{g}( \pm 64.5)$ FP equivalent). Ten subjects returned to complete period 3 .

The mean $\%$ fall in $\mathrm{FEV}_{1}$ following methacholine was 19.1\% (95\% CI 17.3\% to $21.0 \%$ ) and after saline was $1.3 \%$ (95\% CI 1.0 to 3.5 ). Bronchoconstriction increased capsaicin-evoked coughs (geometric mean 8.4 coughs $(95 \%$ CI 6.6 to 10.7) vs 13.9 coughs (95\% CI 10.9 to 17.8), $\quad 34.2 \% \quad$ increase, $\quad \mathrm{p}<0.001)$ (figure 1A). Spontaneous resolution of $\mathrm{FEV}_{1}$ over $60 \mathrm{~min}$ significantly reduced capsaicin-evoked coughs $(\mathrm{p}<0.001$, figure $1 \mathrm{~B})$; each $10 \%$ improvement in $\mathrm{FEV}_{1}$ equated to a reduction of 2.4 coughs. Compared with saline inhalation, capsaicin-evoked coughing made no difference to the mean $\%$ fall in $\mathrm{FEV}_{1}$ after inhaling methacholine (geometric mean $13.7 \% \quad(95 \%$ CI $18.7 \%$ to $8.7 \%)$ vs $12.3 \% \quad(95 \% \quad$ CI $15.7 \%$ to $8.9 \%)$, $\mathrm{p}=0.49$, see online supplementary figure E2). Analysis of spontaneous coughs (when participants were not inhaling capsaicin) also demonstrated more coughs during bronchoconstriction compared with control $(p<0.001$, figure 2 and see online supplementary figure E3).

\section{DISCUSSION}

To our knowledge, this is the first study that has investigated the interaction between acute bronchoconstriction and reflex cough in asthma. Methacholine-induced bronchoconstriction caused a significant increase in capsaicin-evoked cough responses and spontaneous coughing, which gradually resolves as airway calibre returns to baseline. In contrast, capsaicin-evoked coughing had no influence on BHR. Our data therefore challenge the concept that cough reflex responses and bronchoconstriction are independent in asthma.

There are several potential explanations for the findings in this study. First, the mechanical effect of bronchoconstriction on the epithelium, smooth muscle and other structural cells may result in the release of mediators capable of sensitising airway nerves and hence increasing cough responses to capsaicin, for example, ATP and TGF- $\beta .^{6}{ }^{7}$ Second, mechanosensitive afferent nerves in the airways are tonically active during tidal breathing and provide feedback to the central nervous system about changes in lung pressures/volumes. These same fibres are activated by bronchoconstriction and converge with those evoking cough in the brainstem, providing the opportunity to modify cough responses. $^{8}$ Finally, bronchoconstriction alters the deposition of inhaled particles within the airways. ${ }^{9}$ During 
A

Visits 3 and 4
B
Visits 7 and 8

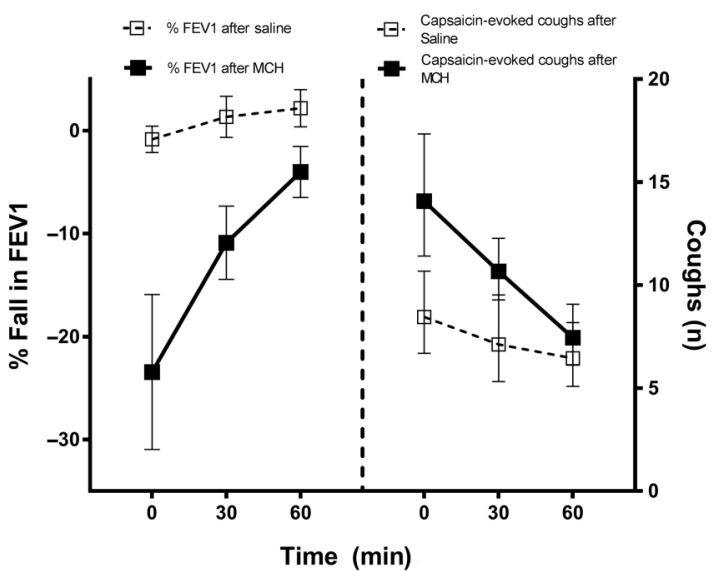

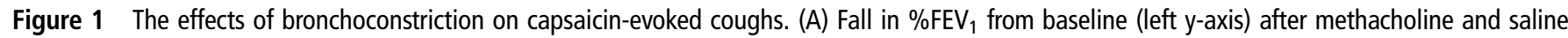
challenge with corresponding capsaicin-evoked coughs (right y-axis). (B) Spontaneous recovery of FEV ${ }_{1}$ after methacholine inhalation shown as arithmetic mean and $95 \% \mathrm{Cl}$ (left y-axis) with corresponding reduction in capsaicin-evoked coughs shown as geometric mean and $95 \%$ Cls (right axis). Cough data were log transformed for analysis to normalise distribution. All data were analysed by generalised estimating equation models adjusted for baseline ED50 coughs; there was no significant effect of gender, period or sequence. MCH, methacholine.

Figure 2 The effects of bronchoconstriction on spontaneous coughs. Visits were divided into five time periods to compare differences in spontaneous coughs; prechallenge spirometry, after methacholine/saline challenge, postchallenge spirometry, postsalbutamol recovery and after the final spirometry. Compared with saline inhalation, significant differences in spontaneous coughs were seen immediately after methacholine inhalation and after performing spirometry subsequently (both $\mathrm{p}=0.001$, marked with asterisk). Coughs shown are arithmetic mean and $95 \% \mathrm{Cl}$. A generalised estimating equation model was used to compare cough frequency between methacholine and saline during time periods when subjects were not inhaling capsaicin.

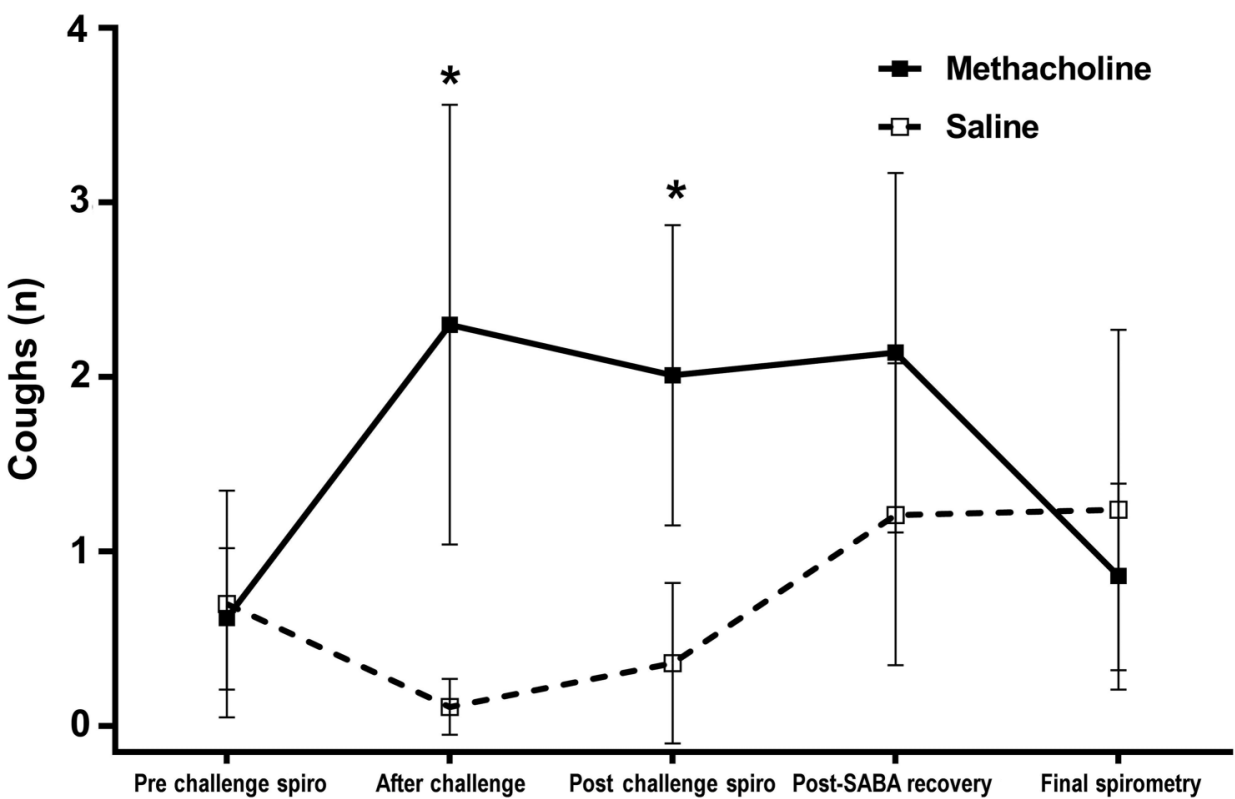

subjects, and it is unclear whether similar results would be achieved in other phenotypes and moderate/severe disease. Third, we deliberately did not measure markers of airway inflammation in sputum or exhaled breath because performing these tests may have interfered with the challenge responses.

In conclusion, this study provides important mechanistic insights about how airway pathophysiology in asthma relates to the development of symptoms through neuronal activation. These data suggest that bronchoconstriction increases the activation of capsaicin-responsive airway nerves, but the precise mechanisms and mediators involved require further evaluation.

Imran Satia, ${ }^{1,2}$ Huda Badri, ${ }^{1}$ Mark Woodhead, ${ }^{1,3}$ Paul M O'Byrne, ${ }^{1,4}$ Stephen J Fowler, ${ }^{1}$ Jaclyn A Smith ${ }^{1,2}$

${ }^{1}$ Division of Infection, Immunity and Respiratory Medicine, University of Manchester and Manchester Academic Health Science Centre, Manchester, UK

${ }^{2}$ University Hospital of South Manchester, Manchester, UK

${ }^{3}$ Central Manchester NHS Foundation Trust,

Manchester, UK

${ }^{4}$ Department of Medicine, McMaster University Hamilton, Ontario, Canada

Correspondence to Professor Jacky A Smith, Centre for Respiratory and Allergy Research, University of Manchester, University Hospital of South Manchester, changes in nerve function. Second, we recruited young mild atopic asthma 
Level 2, Education and Research Centre, Manchester M23 9LT, UK; jacky.smith@manchester.ac.uk

Twitter Follow Imran Satia @lung_research

Acknowledgements The authors would like to thank all the subjects who participated in the study, the National Institute for Health Research (NIHR) South Manchester Clinical Research Facility (CRF) and the NIHR/Wellcome Trust Central Manchester CRF.

Contributors IS, HB, MW, PMO, SJF and JAS: concept and design. IS and HB: data generation. IS and JAS: statistical analysis and modelling. All authors reviewed the manuscript and approved the final draft.

Funding National Institute for Health Research, South Manchester Clinical Research Facility.

Competing interests JAS is a named inventor on a patent, owned by University Hospital of South Manchester, describing a method for generating output data licensed to Vitalograph; however, no financial benefits have been received.

Patient consent Obtained.

Ethics approval North West, Liverpool East Ethics Board (15/NW/0052).

Provenance and peer review Not commissioned; externally peer reviewed.
- Additional material is published online only. To view please visit the journal online (http://dx.doi.org/10. 1136/thoraxjnl-2016-209625).

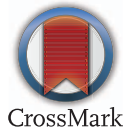

To cite Satia I, Badri H, Woodhead M, et al. Thorax 2017;72:1144-1146.

Received 24 October 2016

Revised 25 January 2017

Accepted 5 February 2017

Published Online First 24 February 2017

Thorax 2017:72:1144-1146.

doi:10.1136/thoraxjnl-2016-209625

\section{REFERENCES}

1 Marsden PA, Smith JA, Kelsall AA, et al. A comparison of objective and subjective measures of cough in asthma. I Allergy Clin Immunol 2008:122:903-7.

2 Satia I, Tsamandouras N, Holt K, et al. Capsaicin-evoked cough responses in asthmatic patients: evidence for airway neuronal dysfunction. J Allergy Clin Immunol 2016

3 Smith CA, Adamson DL, Choudry NB, et al. The effect of altering airway tone on the sensitivity of the cough reflex in normal volunteers. Eur Respir $J$ 1991:4:1078-9.

4 Hilton EC, Baverel PG, Woodcock A, et al. Pharmacodynamic modeling of cough responses to capsaicin inhalation calls into question the utility of the $\mathrm{C} 5$ end point. J Allergy Clin Immunol 2013;132:847-855.e1-5.

5 Crapo RO, Casaburi R, Coates AL, et al. Guidelines for methacholine and exercise challenge testing-1999. This official statement of the American Thoracic Society was adopted by the ATS Board of Directors, July 1999. Am J Respir Crit Care Med 2000:161:309-29.

6 Weigand LA, Ford AP, Undem BJ. A role for ATP in bronchoconstriction-induced activation of guinea pig vagal intrapulmonary C-fibres. J Physiol 2012:590:4109-20.

7 Oenema TA, Mensink G, Smedinga L, et al. Cross-talk between transforming growth factor- $\beta_{1}$ and muscarinic $M_{2}$ receptors augments airway smooth muscle proliferation. Am J Respir Cell Mol Biol 2013;49:18-27.

8 Mazzone SB, Mori N, Canning BJ. Synergistic interactions between airway afferent nerve subtypes regulating the cough reflex in guinea-pigs. I Physiol 2005:569(Pt 2):559-73.

9 Usmani OS, Biddiscombe MF, Barnes PJ. Regional lung deposition and bronchodilator response as a function of beta2-agonist particle size. Am J Respir Crit Care Med 2005:172:1497-504. 